\title{
Comorbidities with Congenital Heart Disease among Hospitalized Children in a Specialized Cardiac Hospital in Bangladesh
}

\author{
Shahina Akhter Mita ${ }^{1}$, Md. Salim² ${ }^{2}$ Md. Ataul Haque ${ }^{3}$, Abdullah Shahriar ${ }^{3}$, Md. Nazneen Umme \\ Zakia $^{3}$, ABM Abdus Salam ${ }^{3}$, AZM Raihanur Rahman, Abul Hasnat Md. Jafar ${ }^{3}$ \\ ${ }^{1}$ Mugda Medical College Hospital, Dhaka, ${ }^{2}$ Dhaka Medical College, Dhaka, ${ }^{3}$ National Institute of \\ Cardiovascular Diseases, Dhaka
}

\begin{abstract}
:
Key word: Congenital heart disease, Comorbidities, Down syndrome

Background: Congenital heart diseases (CHD) when associated with any comorbid condition may complicate the outcome of management. So to find out and treat comorbidities before definite treatment is essential for better outcome.

Methods: This observational cross sectional study was conducted in the inpatient Department of Paediatric Cardiology at National Institute of Cardiovascular Diseases, Dhaka, during the period of January 2014 to January 2015 to identify the comorbid conditions of congenital heart disease.

Results: A total of 794 children with different types of congenital heart disease were enrolled during the study period. Among them, 48.6\% were simple CHD and 51.4\% were complex CHD. Among simple CHD, ventricular septal defect (VSD) was commonest (27.2\%), Tetralogy of Fallot (TOF) occupied the second position (20.5\%). One child presented with Ectopia cardis. Among complex CHD most common anomalies were VSD with either atrial septal defect (ASD) or patent ductus arteriosus (PDA) or valvular lesion. Next common anomalies were TOF with PDA or ASD \&/or pulmonary valvular abnormalities. Double outlet of right ventricle (DORV) with shunt and transposition of great arteries (TGA) with shunt also occur frequently. AV canal defect with or without valvular lesion presented in significant number. Among them 616 (77.6\%) had different types of comorbid conditions. Among comorbidities, respiratory and acquired cardiac comorbidities were common $(37.9 \%$ \& $34.1 \%$ respectively). Other congenital or genetic comorbidities were in $11.2 \%$. Multisystem involvement was in $9.8 \%$ cases.

Conclusion: Pneumonia and heart failure were the most frequent comorbid condition among both simple and complex congenital heart disease. They were common among acyanotic heart disease. But cyanotic spell, acute stroke syndrome and brain abscess were common among cyanotic heart disease. Among genetic comorbidities Down's syndrome occupied the major part.
\end{abstract}

(Cardiovasc.j. 2017; 9(2): 83-89)

\begin{abstract}
Introduction:
Congenital heart disease is the most common cause of major congenital anomalies, representing a major global health problem. Twenty eight percent of all major congenital anomalies consist of heart defect. ${ }^{1}$ Despite remarkable progress in clinical care for affected individuals, CHD remains the leading cause of infant mortality among birth defects. ${ }^{2}$ For those that survive infancy, there is a high rate of comorbidities, both cardiac and extra cardiac, and expected lifespan is still diminished. ${ }^{3}$ These issues have become increasingly important,
\end{abstract}

as the number of adults with CHD now exceeds the number of children with CHD. ${ }^{4}$ Between $25 \%$ to $30 \%$ of children with CHD have some form of additional congenital lesion, a comorbidity or structural extra cardiac anomaly (ECA) that may or may not be immediately apparent. However, comorbidity may have an important, even crucial, bearing on the course and outcome of the management of a child with a congenital heart lesion. ${ }^{5}$ It is known that in recent years there has been an increase in the number of surgery on correction of congenital heart defects in children

Address of Correspondence: Dr. Md. Salim, Dept. of Paediatrics, Dhaka Medical College, Dhaka, Bangladesh. Emailsalimita2001@yahoo.com 
during the first years of life due to advances in Pediatric Cardiac Surgery and it is associated with the expansion of early surgical care. ${ }^{6,7}$ The state of the operated child, as well as the duration of rehabilitation therapy, is not only determined by the peculiarities of cardio-vascular system, the volume and specific features of interven-tion, but by the presence of concomitant pathology. So, now a day, a great attention is paid to comorbid diseases in association with congenital heart disease. ${ }^{8}$ There are insufficient studies available regarding children with congenital heart defect with other comorbid conditions in our Country. National Institute of Cardiovascular disease (NICVD), Dhaka provides the highest service to the patients with CHD in Bangladesh. So this study was designed to observe the situation of $\mathrm{CHD}$ and their comorbid conditions in this hospital where patients are being referred from different corners of the country, and it will provide the exact presentation of comorbidities among children with CHD in our country.

\section{Methods:}

This observational cross sectional study was conducted in the inpatient Department of Paediatric Cardiology at NICVD, Dhàkà, during the period of January 2014 to January 2015. All children aged $<15$ years with known CHD or suspected to have heart disease who were admitted in this hospital due to different co-morbid conditions were enrolled in this study. But the children with acquired heart disease like rheumatic valvular disease or viral myocarditis or isolated pericardial effusion with co-morbidities were excluded from this study. Samples were selected purposively. A total of 987 children were admitted during this period. All new and old cases were diagnosed by color Doppler echocardiography done by expert pediatric cardiologist in this hospital. Finally 794 children with different types of CHD were identified and enrolled in this study. After registration, a detailed history and clinical examinations were done to find out the comorbidities along with congenital heart disease. Then laboratory investigations, both routine and special were done to reach a final diagnosis. Comorbidities were categorized as congenital/genetic, respiratory, cardiac, gastrointestinal, renal, haematological, neurological, endocrine and multisystem comorbidities. Data were collected by using a semi structured questionnaire. Verbal consent was taken from patient and their guardian before registration. SPSS 11.5 were used for analysis the data.

\section{Results:}

A total of 794 children were studied. Among them $4.3 \%$ were neonates, $27.2 \%$ were infants and most of the children were in between $1-5$ years $(32.9 \%)$ and 5-10 years (27.8\%) age group. Only $7.8 \%$ children were enrolled who reached puberty and adolescent in $>10$ years age group. Among studied children $51.3 \%$ were male and $48.7 \%$ were female. In this study, 386 (48.6\%) children were presented with simple CHD having single defect and 408 (51.4\%) children had complex CHD having multiple defects. Among simple CHD, VSD were commonest (29.0\%), TOF occupied the second position (23.3\%). Among valvular lesion (3.4\%) bicuspid aortic valve (BAV) with aortic stenosis (AS) or aortic regurgitation (AR), congenital mitral stenosis (MS) or mitral regurgitation (MR), pulmonary stenosis (PS) \& tricuspid regurgitation (TR) were present. There were $4.1 \%$ children had Coarctation of Aorta (CoA). One child presented with Ectopia cordis in this study.

\section{Table-I}

Distribution of different simple congenital heart disease $(n=386)$.

\begin{tabular}{lcc}
\hline CHD & Frequency & Percent \\
\hline VSD & 112 & 29.0 \\
ASD & 71 & 18.4 \\
PDA & 83 & 21.5 \\
TOF & 90 & 23.3 \\
Valvular Lesion & 13 & 3.4 \\
CoA & 16 & 4.1 \\
Other (Ectopia Cordis) & 1 & 0.3 \\
\hline Total & 386 & 100.0 \\
\hline
\end{tabular}

Among complex CHD multiple defect were identified. Most common anomalies were VSD with either ASD or PDA or any valvular lesion. Next common anomalies were TOF with PDA or ASD \&/or pulmonary valvular abnormalities. DORV with shunt and TGA with shunt also occur frequently. A-V canal defect with or without valvular lesion occur in significant number. 


\section{Table-II}

Distribution of different complex congenital heart disease $(n=408)$.

\begin{tabular}{|c|c|c|}
\hline Complex CHD & Frequency & Percent \\
\hline$\overline{\mathrm{VSD}+\mathrm{ASD}}$ & 49 & 12.0 \\
\hline VSD+PDA & 34 & 8.3 \\
\hline VSD+ASD+PDA & 24 & 5.9 \\
\hline VSD+Valvualr lesion & 22 & 5.4 \\
\hline ASD+Valvular lesion & 13 & 3.2 \\
\hline PDA+ valvular lesion & 16 & 3.9 \\
\hline VSD+ASD/PDA+ valvular lesion & 23 & 5.6 \\
\hline $\mathrm{TOF}+\mathrm{ASD}$ & 9 & 2.2 \\
\hline $\mathrm{TOF}+\mathrm{PDA}$ & 31 & 7.6 \\
\hline TOF+Hypoplastic PA & 24 & 5.9 \\
\hline Single Ventricle & 5 & 1.2 \\
\hline DORV+VSD/ASD/PDA & 23 & 5.6 \\
\hline DORV+VSD/ASD/PDA+ Valvular lesion & 8 & 2.0 \\
\hline DORV+ PS & 18 & 4.4 \\
\hline TGA+VSD/ASD/PDA & 30 & 7.4 \\
\hline TGA+VSD/ASD/PDA+ & 8 & 2.0 \\
\hline \multicolumn{3}{|l|}{ Valvular lesion } \\
\hline A-V Canal Defect & 22 & 5.4 \\
\hline A-V Canal defect + Valvular lesion & 6 & 1.5 \\
\hline Ebstein anomalies+ASD/PDA & 13 & 3.2 \\
\hline $\mathrm{EA}+\mathrm{ASD} / \mathrm{PDA}+$ valvular lesion & 3 & 0.7 \\
\hline Truncus+ VSD/ASD/PDA & 8 & 2.0 \\
\hline TA+ASD/VSD/PDA+ & 3 & 0.7 \\
\hline \multicolumn{3}{|l|}{ valvular lesion } \\
\hline TAPVC/PAPVC+ASD & 16 & 3.9 \\
\hline Total & 408 & 100.0 \\
\hline
\end{tabular}

\section{Comorbidities:}

Among 794 children with different type of CHD, $616(77.6 \%)$ children were admitted due to some associated comorbid condition but 178 children had no comorbidities. These 178 children were admitted for preoperative investigation (Cardiac catheterization) or cardiac interventional purpose (device/coil closure of defect or valvuloplasty). Among comorbidities, respiratory and cardiac comorbidities were common $(37.9 \%$ \& $34.1 \%$ respectively). Congenital or genetic comorbidities were $11.2 \%$. Multisystem involvement occurs in $9.8 \%$ cases.

\section{Congenital/Genetic Comorbidities}

Among congenital/Genetic abnormalities, Children with Down's syndrome were commonest (47.9\%), next frequent abnormalities were congenital rubella syndrome (16.9\%). Cleft lip \& or Cleft palate were found in $11.3 \%$ cases. Turner, Noonan's, Edward \& Marfans syndrome were identified, two in number of each syndrome. Five cases were identified with Hirschprung disease along with CHD. One Carvezal syndrome was diagnosed along with DCM with MVP with MR. 


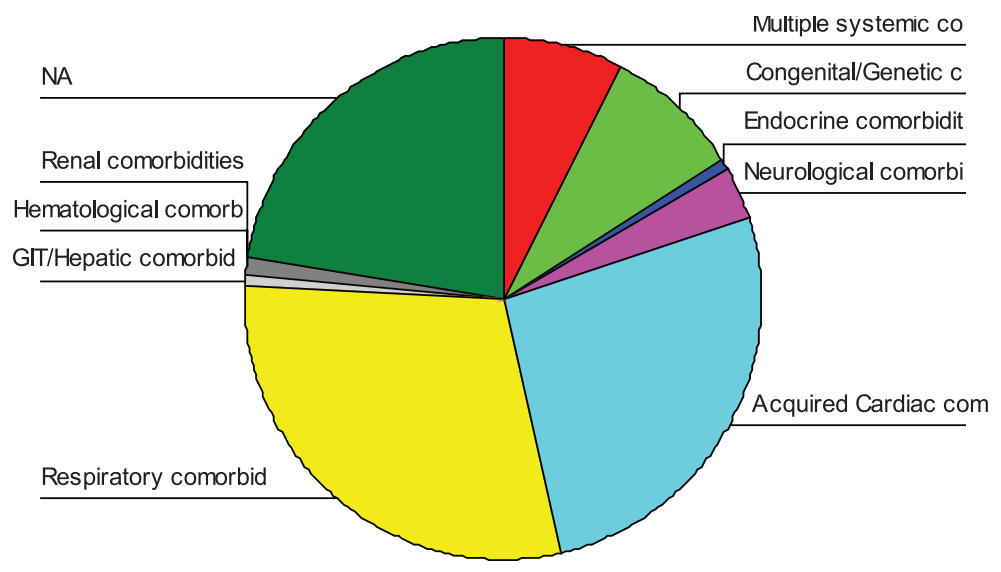

Fig.-1: Comorbidities associated with CHD.

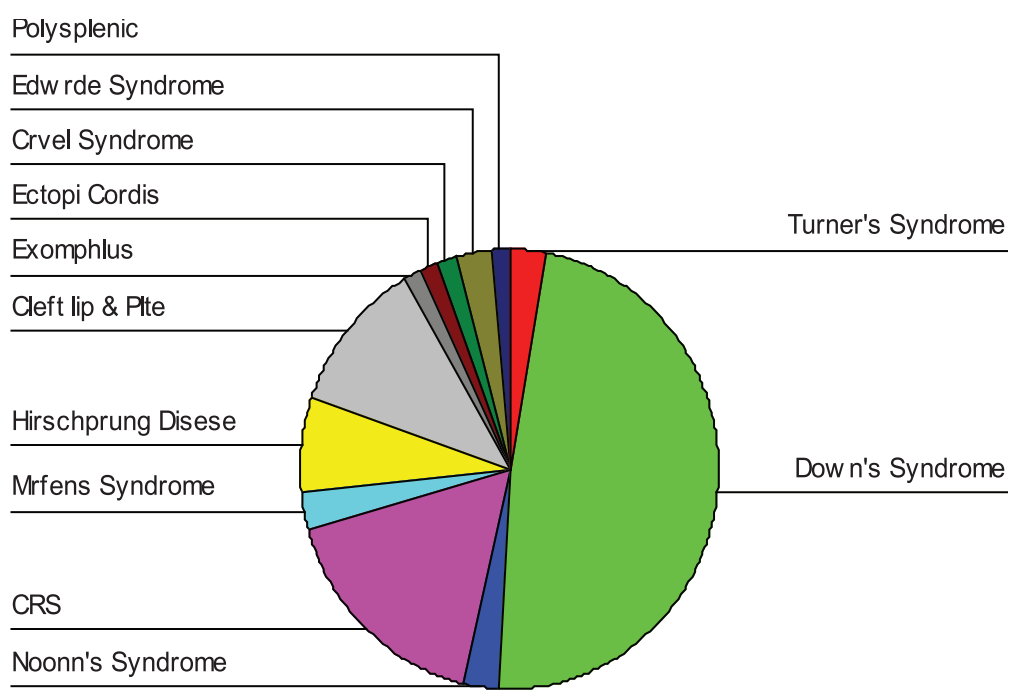

Fig.-2: Congenital/Genetic abnormalities.

\section{Respiratory Comorbidities}

In this study 309 (37.9\%) children were admitted due to respiratory problems along with congenital heart diseases. Among them pneumonia accounted for $64.7 \%$, Bronchiolitis $25.9 \%$ and pulmonary TB $2.1 \%$. Others were Bronchial asthma and pleural effusion. Pneumonia \& bronchiolitis were more commonly associated with complex CHD and bronchial asthma, pleural effusion and pulmonary TB were more common in simple CHD.

\section{Cardiac comorbidities}

Among cardiac comorbidities, 154 patients with simple CHD and 143 patients with complex CHD presented with different types of presentation. Heart failure, infective endocarditis and cyanotic spell were common presentation in both simple and complex CHD. Cyanotic spell were associated with RVOT obstruction. Patients present with shock were more common in complex CHD. Arrhythmia and pericardial effusion along with congenital heart disease also presented as a cardiac comorbidities.

Other comorbidities:

Among neurological comorbidities 24 patients in simple CHD and 12 patients in complex CHD presented with different presentation. Brain abscess and acute stroke syndrome were more common. Both were associated with TOF with or without other anomalies. Among other comorbidities, 6 patients presented with 


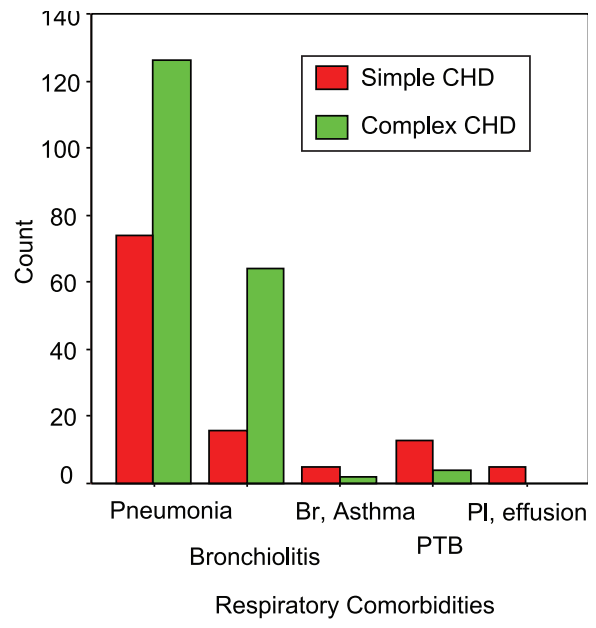

Fig.-3: Respiratory comorbidities with CHD

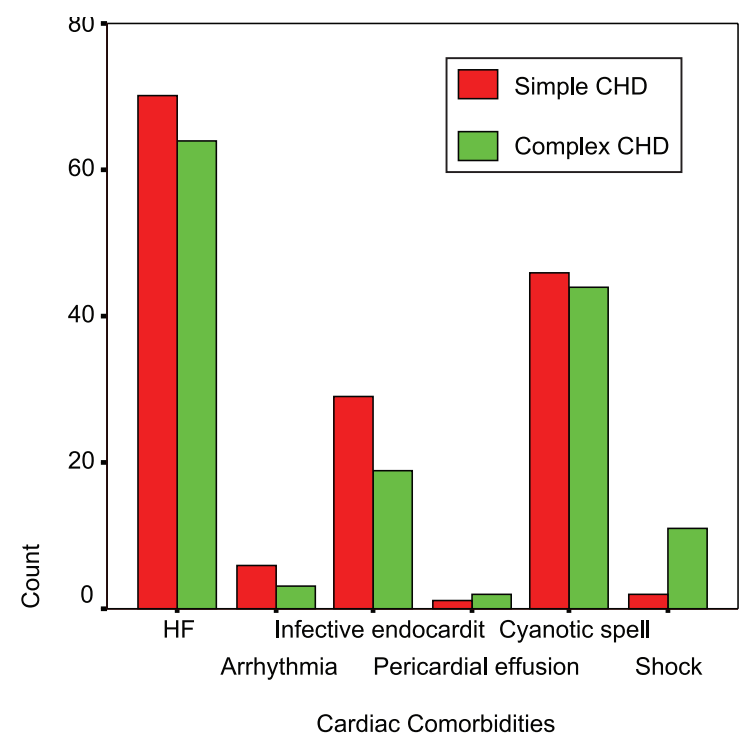

Fig.-4: Cardiac comorbidities with CHD.

hypothyroidism, 6 with hepatitis (Acute hepatitis 5 and CLD 1) 2 with chronic diarrhea, 31 patients with septicemia, 3 with aplastic anaemia, 4 with bleeding manifestations, 12 patients with kidney diseases ( AKI 7, CKD 2 \& AGN 3). Multisystem involvement occur in $9.8 \%$ cases in the form of concurrent involvement of two or more system, like respiratory (e.g. Pneumonia), cardiac (e.g. heart failure, arrhythmias, cardiogenic shock etc), Renal (e.g. AKI), hematological (e.g. anemia, bleeding manifestations or shock) or metabolic (hypoglycemia, hypocalcaemia, acidosis or alkalosis).

\section{Discussion:}

CHDs are an important subgroup of the congenital malformations since they carry a high risk of mortality and morbidity when it is associated with comorbid condition. ${ }^{9}$ In this study most patients admitted with congenital heart defects were infants, followed by toddlers and preschoolers. Only 7.8\% children were enrolled who reached puberty and adolescent in $>10$ years age group. Adrian $\mathrm{Hru}^{\circ}$ cã et al. also showed that most of the children in his study were toddler to young children below 10 years of age ${ }^{10}$ However, it should be noted that, in developed countries, congenital heart defects are often caught during the neonatal phase or at birth. ${ }^{11}$ But due to inadequate facilities, neonatal diagnosis could not be possible in our country. In this study, $48.6 \%$ children were presented with simple CHD and $51.4 \%$ children had complex CHD having multiple defects. Among simple CHD, VSD were commonest (29.0\%), TOF occupied the second position (23.3\%). There were $4.1 \%$ children had CoA. One child presented with Ectopia cordis in this study. Among complex CHD most common anomalies were VSD with either ASD or PDA or any valvular lesion. Next common anomalies were TOF with PDA or ASD \&/or pulmonary valvular abnormalities. DORV and TGA with shunt also occur frequently. AV canal defect with or without valvular lesion occur in significant number. This result correlates with other studies, where they showed more than half of the children presented with complex CHD and VSD were the commonest among simple CHD. ${ }^{12-14}$ But Islam MN et al. showed that, most (92\%) CHD were simple. ${ }^{15}$ Among simple CHD, VSD was the commonest followed by ASD then PDA \& TOF. Among Complex CHD, TGA with shunt were common. Rashmi K \& Shipra G also showed the similar results. ${ }^{16}$ But our study differs from some other studies where they found ASD was the commonest lesion. ${ }^{17-19}$ This difference in observation might be due to that Rahman et al. and Siddique et al. included many adult patients in their study. A significant proportion of VSD close spontaneously before adulthood and some untreated patients with large VSD die in childhood from heart failure. On the other hand ASD patients may remain asymptomatic in childhood and are diagnosed for the first time when they are adult. The study subjects of Fatema et al. were all newborn and many small sized VSD and most of the child with TOF may not manifest by that time. ${ }^{19}$ 
In this series $77.6 \%$ children were admitted due to some associated comorbid condition along with CHD. Among comorbidities, respiratory and cardiac comorbidities were common $(37.9 \%$ \& $34.1 \%$ respectively). Congenital or genetic comorbidities were $11.2 \%$. Multisystem involvement occurred in $9.8 \%$ cases. Among congenital/Genetic abnormalities, children with Down's syndrome were commonest (47.9\%), next frequent abnormalities were congenital rubella syndrome (16.9\%). Cleft lip \& or Cleft pàlàte were found 11.3\%. Turner, Noonan's, Edward \& Marfan's syndrome were also identified. Five cases were identified with Hirschprung disease along with CHD. One Carvezal syndrome was diagnosed along with DCM with MVP with MR. Extra cardiac abnormalities are frequently detected in children with CHD. Skeletal abnormalities, especially those of the hand and arm, are often associated with cardiac malformations. CHD may be a component of many specific syndromes and chromosomal disorders. ${ }^{20}$ In a review of the population-based surveillance data from the Metropolitan Atlanta Congenital Defects Program, 12.3 percent of infants with CHD had a chromosomal abnormality. Infants with genetic disorders associated with cardiovascular malformations should be evaluated for possible cardiac abnormalities. ${ }^{21}$ Hussain at $e l$. showed the co-morbid problem in CHD among 224 children in Bangladesh in their study, 21.2\% children had co-morbidities. ${ }^{22}$ Among them $11.2 \%$ had genetic or syndromic conditions, of which mostly had Trisomy 21 . The most frequent associated conditions were mental retardation, asthma, epilepsy and scoliosis. Islam MN et al. showed the associated non-cardiac anomalies. ${ }^{15}$ Down's syndrome was noticed in $6 \%$ cases, polydactyly and syndactyly were detected in $4 \%$ newborn. Cleft lip with palate, cataract and renal anomaly were also found in $2 \%$ cases respectively. Comorbidities along with CHD in our study was also almost similar to other studies. ${ }^{23,24}$

Danford DA \& McNamara DG showed in neonates with critical CHD may present during their birth, hospitalization with serious and life-threatening manifestations including shock, cyanosis, or respiratory signs and symptoms of pulmonary edema. ${ }^{25}$ However, some infants with CHD may appear normal on routine examination and signs of critical CHD may not be apparent.
Adrian $\mathrm{Hru}^{\circ} \mathrm{cã}$ et al. study showed the largest part of congenital heart defects do not associate with other types of abnormalities, but when they do, the most frequent associations are made with: craniofacial deformities, bone and muscle defects, gastrointestinal, renal, genital abnormalities, hemangiomas, ophthalmological abnormalities and lung malformations. ${ }^{10}$ As far as syndromes are concerned, the highest incidence rate is recorded for Down syndrome, followed by the Turner syndrome and the Noonan, Marfan's and Pierre Robin syndromes. Aneuploidies such as trisomy 21 (causing Down's syndrome) are strongly associated with CHD. ${ }^{26}$ Our study findings are also consistent with this study.

\section{Conclusion:}

Pneumonia and heart failure were the most frequent comorbid conditions among both simple and complex congenital heart disease. These were common among acyanotic heart disease. But cyanotic spell, acute stroke syndrome and brain abscess were common among cyanotic heart disease. Among genetic comorbidities Down's syndrome occupied the major part.

\section{Conflict of Interest - None.}

\section{References:}

1. Dolk H, Loane M, Garne E. For the European Surveillance of Congenital Anomalies (EUROCAT) working Group. Congenital heart defects in Europe: prevalence and perinatal mortality, 20002005.Circulation 2011;123:841-849.

2. Yang Q, Chen H, Correa A, Devine O, Mathews TJ, Honein MA. Racial differences in infant mortality attributable to birth defects in the United States, 19892002. Birth Defects Res Part A Clin Mol Teratol 2006;76:706-713.

3. Tennant PW, Pearce MS, Bythell M, Rankin J. 20-year survival of children born with congenital anomalies: a population-based study. Lancet 2010;375:649-656.

4. Williams RG, Pearson GD, Barst RJ, Child JS, del Nido P, Gersony WM, et al. Report of the National Heart, Lung, and Blood Institute Working Group on research in adult congenital heart disease. $J$ Am Coll Cardiol 2006;47:701-707.

5. Formigari R, Michielson G, Digilio MC, et al. Genetic syndromes and congenital heart defects: how is surgical management affected? Eur J Cardio-Thorac 2009; 35: 606-614. 
6. Boqueria La, Tumanyan MR, Trunina II. Not surgical risk factors in newborns with congenital heart diseases. Children's Cardiology 2012, Tez. (VII) All. Congress M; 2012: 9-11.

7. Doronina TN, Cherkasov NS. Importance of comorbidity in chil-dren with congenital heart diseases. Actual problems of Pediatrics: Materials the 16th Congress of Pediatricians of Russia with international participation. Moscow; 2012: 821

8. Namazova HP, Arshba SK, Akoev JS. Modern aspects of concomitant pathology in children. Reference the Pediatrician 2008; 4: 5-21.

9. Petrini J, Damus K, Russell R, et al. Contribution of birth defects to infant mortality in the United States. Teratology 2002; 66 (Suppl): S3-6.

10. Hru ${ }^{\circ}$ cã A, Cãinap S, Andreea L, Tudor R, Pop L, Chira $\mathrm{M}$, et al. Congenital heart defects and associated comorbidities -5 years of experience. HVM Bioflux $S$ 2013;5(2): 62-65

11. Ferencz C, Rubin JD, Meconter RJ. Congenital Heart Diseases. Prevalence at live birth. The Baltimore Washington infant study. Am J Epidemiol 1985;121:3136.

12. Mitchell SC, Korones SB, Berendes HW. Congenital heart disease in 56,109 births. Incidence and natural history. Circulation 1971;43:323-332.

13. Mollah MAH, Begum NA, Islam MN, et al. Clinical profile of congenital heart diseases (CHD): an Analysis of 218 cases. Bangladesh Heart Journal 2002;17:62-7.

14. Hussain M, Hossain M, Amin SK, et al. Pattern of congenital heart disease in Dhaka Shishu Hospital. DS (Child) $H J$ 1992;8:35-46.

15. Islam MN, Hossain MA, Khaleque MA, Das MK, Khan MRH, Bari MS, et al. Prevalence of Congenital Heart Disease in Neonate in a Tertiary Level Hospital. NJMS 2013; 2(2):91-95.

16. Rashmi K and Shipra G. Prevalence of Congenital Heart Disease, Kanpur, India. Indian Pediatrics 2008; 45:309311

17. Rahman S, Ahmed MN, Rahmatullah KHI, et al. The prevalence of congenital heart diseases diagnosed by
Non-invasive technique- Ten years study in Bangladesh. DS (Child) H J 1992;8:5-15.

18. Siddique FM, Kamal SMM, Huq KMHSS. Clinical presentation of congenital heart diseases in hospitalized patients. Bangladesh Heart Journal 1989;4:13-17.

19. Begum NNF, Ahmed QS. Pattern of heart diseases among neonates and their outcome: One year experience in non-invasive cardiac laboratory of combined military hospital, Dhaka. Bangladesh J Child Health 2001; 25:48-52.

20. Pierpont ME, Basson CT, Benson DW Jr, et al. Genetic basis for congenital heart defects: current knowledge: a scientific statement from the American Heart Association Congenital Cardiac Defects Committee, Council on Cardiovascular Disease in the Young: endorsed by the American Academy of Pediatrics. Circulation 2007; 115:3015.

21. Hartman RJ, Rasmussen SA, Botto LD, et al. The contribution of chromosomal abnormalities to congenital heart defects: a population-based study. Pediatr Cardiol 2011; 32:1147.

22. Hussain M, Tahura S, Sayeed MA. Past \&Present pattern of congenital heart disease at Dhaka Shishu Hospital:A situation analysis. Bangladesh J Child Health 2010; 34(2):51-55.

23. Hoffman JIE. Congenital heart disease: Prevalence and inheritence. Pediatr Clin North Amer 1990; 37: 25-43.

24. Bound JP, Logan WF. Prevalence of congenital heart disease in black pool: 1957-1971. Brit Heart J 1977; 39:445-450.

25. Danford DA, McNamara DG. Infants with congenital heart disease in the first year of life. In: Garson A, Bricker JT, Fisher DJ, Neish SR. Eds. The Science and Practice of Pediatric Cardiology. Baltimore: Williams \& Wilkins, 1998: 2228.

26. Goldmuntz E, Paluru P, Glessner J, Hakonarson H, Biegel JA, White PS. Microdeletions and microduplications in patients with congenital heart disease and multiple congenital anomalies. Congenit Heart Dis 2011; 6:592-602. 